\title{
TOWARDS ADJUSTMENTS IN UNIVERSITY RANKINGS, COMPUTER SCIENCE FIELD
}

\author{
Sónia Rolland Sobral \\ REMIT, Universidade Portucalense (PORTUGAL) \\ doi: $\underline{10.21125 / \text { inted.2020.2164 }}$
}

Every year we are flooded with different university rankings that are available to everyone in the internet: pre-college youths and their families, teachers/researchers, and investors/governments eagerly consult these lists. A university ranking is a system that lists some universities according to certain items and weights. These items can be scientific production, awards received by staff or alumni, or based on credibility reports. Each ranking gives importance to different characteristics and the corresponding result is also very different. Those who read the result of these rankings often do not know how they are created and become confused with such diversity.

Ranking results are dependent on several points, namely the database that is used, as well as the greater or lesser dependence on scientific production. In previous studies, we found that the greater weight of the WebOfScience database, the higher the chances are that the results turn to a large number of Asian universities present in the top places. Conversely, greater the weight of the Scopus database, lesser the number of Asian universities in these top places, usually occupied by universities in the United States and some universities in Europe.

This article attempts to adjust these rankings by using a more equitable weight among the most important databases in the academic world. The results will be presented only for the computer science subarea and will be completely dependent on the scientific output of the universities.

keywords: university rankings, computer science, web of science, scopus. 